\title{
Influência do ciclo de vida do produto em relação à classificação de clientes para planejar estratégias de venda: o caso de um comércio varejista de calçados e acessórios
}

\author{
Wellington Pereira Godinho Neto \\ Graduação em Administração pelo Centro Universitário Estácio do Ceará \\ E-mail:wgtong@gmail.com
}

Rosângela Venâncio Nunes Mestrado em Logística e Pesquisa Operacional pela Universidade Federal do Ceará - UFC Professora do Centro Universitário Estácio do Ceará Av. Duque de Caxias, 101. Centro. Fortaleza/CE. CEP: 60035-111 E-mail: angelnuness@gmail.com

Charles Washington Costa de Assis Especialização em Auditoria pela Universidade Federal do Ceará - UFC Professor do Centro Universitário Estácio do Ceará Av. Duque de Caxias, 101. Centro. Fortaleza/CE. CEP: 60035-111 E-mail: charles-cont@hotmail.com

Rita de Cassia Fonseca Mestrado em Engenharia de Produção pela Universidade Tecnológica Federal do Paraná - UTFPR Professora da Universidade Estadual do Centro Oeste - Paraná E-mail: ritadecfonseca@gmail.com

Nayana de Almeida Adriano Mestrado em Ciências Contábeis pela Universidade de Brasília - UNB Professora do Centro Universitário Estácio do Ceará Av. Duque de Caxias, 101. Centro. Fortaleza/CE. CEP: 60035-111 E-mail: nayanaadriano@hotmail.com

\section{RESUMO}

Este artigo tem como objetivo analisar a influência do ciclo de vida do produto em relação à classificação de clientes para planejar estratégias de venda. A metodologia escolhida para a realização do trabalho foi baseada tanto no método científico dedutivo quanto no indutivo. A pesquisa adotada é de natureza qualitativa, pois se trata de um estudo de caso. No estudo, foi apontado o ciclo de vida de produtos da Meia Sola Acessórios de Moda, sua relação com o cliente e as decisões tomadas, baseadas no seu estudo. Percebeu-se que o ciclo de vida do produto está diretamente ligado ao lucro da empresa; assim sendo, sua análise é de fundamental relevância, pois uma percepção errada pode fazer com que a empresa deixe de vender ou alcançar 
Influência do ciclo de vida do produto em relação à classificação de clientes para planejar estratégias de venda: o caso de um comércio varejista de calçados e acessórios Wellington Pereira Godinho Neto, Rosângela Venâncio Nunes, CharlesWashington Costa de Assis, Rita de Cassia Fonseca, Nayana de Almeida Adriano

determinado público. Nesse sentido, o estudo pode concluir que sua análise é necessária quando a organização realiza seu planejamento de marketing, pois, a partir de sua conexão com as classes sociais de seu público-alvo, pode aproveitar todos os seus estágios, incluindo o declínio, estágio mais crítico e menos aproveitado dos produtos.

Palavras-chave: Ciclo de vida do produto. Classificação de clientes. Gestão de resultados. Moda feminina.

\section{Analysis of the life cycle of the product and customer classification as tools to plan sales strategies applied in the context of fashion products - The case of a retailer trade of footwear and accessories}

\section{ABSTRACT}

This article aims to analyze the influence of the product life cycle in relation to the classification of customers to plan sales strategies. The methodology chosen to carry out the work was based on both the deductive scientific method. The research adopted is characterized as qualitative, since it is a case study. In the study, it was appointed the life cycle of products from the Half Sole Fashion Accessories, its relationship with the customer and the decisions based on their study. It was noticed that the product life cycle is directly linked to the profit of the company. Therefore, its analysis is of fundamental importance, because a wrong perception may cause to the company fails to sell or reach a certain audience. In this sense, the study may conclude that its analysis is necessary when the organization carries out its marketing plan, as from its connection to the social class of its target audience it can enjoy all its stages, including the decline, which is a more critical and less advantage stage of the products.

Keywords: Product Life Cycle. Customer rating. Results Management. Feminine Fashion.

\section{INTRODUÇÃO}

A moda exerce forte influência no dia a dia da população e está presente em muitas das ações, que vão desde o modo de se vestir até mesmo a maneira que modifica a forma de comunicação. Conforme Girão (2011, p. 5), "a moda é um mundo sem diferenças entre pessoas, classes e posses. A moda une, pacifica, se estende como um manto que protege e iguala as pessoas". Entendendo melhor essa afirmação, 
Influência do ciclo de vida do produto em relação à classificação de clientes para planejar estratégias de venda: 0 caso de um comércio varejista de calçados e acessórios Wellington Pereira Godinho Neto, Rosângela Venâncio Nunes, CharlesWashington Costa de Assis, Rita de Cassia Fonseca, Nayana de Almeida Adriano

pode-se observar que as classes sociais podem se igualar utilizando os mesmos produtos.

O setor da moda torna-se mais competitivo a cada dia, com várias marcas surgindo e as semelhanças entre os produtos cada vez maiores. Com isso, o poder de barganha dos clientes cresce proporcionalmente, tornando-os peças-chave no planejamento das estratégias de vendas. Entre 2008 e 2012, o número de empresas têxteis e confeccionistas em atividade no Brasil cresceu 18,4\%, tendo o Ceará como destaque no setor (CAVALCANTE, 2013). As diversas lojas e fábricas vêm em constante esforço para identificar meios que possam se tornar diferenciados e, assim, alavancar seus status e vendas. Esse processo passa pelo planejamento do produto e identificação do público ao qual se dedicará, visto que, nesse setor, a variedade é ampla.

A busca pelo sucesso existe em qualquer setor e, para um empreendimento de moda, não é diferente. No setor da moda, que se desenvolve constantemente assim como se torna competitiva a cada dia, faz-se necessária a busca de estratégias para melhor planejar as vendas. Entre as ferramentas, destacam-se componentes do Mix de Marketing, os 4 Ps (produto, preço, praça e promoção), assim como a força de vendas. Esta última se destaca não apenas pelo grau de planejamento, mas também pela prática imposta pela chamada frente de loja, os vendedores e consultores de moda. Conforme Kotler (2006, p. 143), "Uma das mais dispendiosas ferramentas de comunicação de marketing é a força de vendas da empresa".

Uma tendência no mercado de moda é o surgimento de empresas que se aproveitam do mesmo produto, em estágio diferente do ciclo de vida, para atingir diferentes classes sociais. Birman (2011) aponta que o grupo AREZZO busca novas marcas (para aquisição) que possam ser rentáveis, inclusive na classe $C$, porque é o consumidor que mais cresce. O grupo Arezzo, em 2008, lançou a marca Ana Capri, marca mais acessível que as outras do grupo.

Seguindo essa linha, a empresa franqueada, Meia Sola Acessórios de Moda, localizada no Ceará - objeto de estudo desse trabalho, abriu, em 2009, a loja Pop Club 
Influência do ciclo de vida do produto em relação à classificação de clientes para planejar estratégias de venda: 0 caso de um comércio varejista de calçados e acessórios Wellington Pereira Godinho Neto, Rosângela Venâncio Nunes, CharlesWashington Costa de Assis, Rita de Cassia Fonseca, Nayana de Almeida Adriano

destinada a uma classe diferente das outras lojas que possuíam. No entanto, diferente da franqueada, que tem uma marca própria para o público $C$, os produtos são os mesmos, mas em um "estágio de vida avançado".

Dentre os estudos já realizados sobre o tema, como a relevância da análise do ciclo de vida do produto para a gestão logística no segmento de moda feminina no Ceará, o caso Colmeia Confecções, desenvolvido por Girão (2011), concluiu que o produto de moda necessita de uma logística eficiente para garantir a venda na fase em que o seu ciclo gerasse maior lucro. Outro estudo que merece destaque é a fase da "Liquidação" como estratégia de venda no varejo de moda, desenvolvido por Nascimento (2012). Observa-se como essa estratégia de vendas pode evitar a venda do produto em uma fase que seria menos atrativa financeiramente, bem como a empresa já tivesse despendido mais recursos ao longo do tempo para estocá-lo.

Dessa forma, vale ressaltar a necessidade da definição de estratégias para o tratamento de produtos de moda que estão em descontinuidade, ou mesmo, da forma de classificar os clientes para possíveis vendas.

Nesse contexto, surge o problema que o presente estudo pretende esclarecer: Como a análise do ciclo de vida do produto e a classificação de clientes podem contribuir para que um comércio varejista de calçados e acessórios possam planejar estratégias de venda de seus produtos para melhor gerir os seus resultados?

A partir da indagação feita, o estudo possui como objetivo principal identificar a contribuição que a análise do ciclo de vida do produto e a classificação de clientes oferecem para planejamento de estratégias de venda na busca da melhoria de resultados em um comércio varejista de calçados e acessórios. Para que o objetivo possa ser atingido, fez-se necessário discorrer sobre gestão de resultados e estratégias de planejamento de vendas, assim como conceituar a análise do ciclo de vida de um produto e apresentar suas aplicações e identificar como a análise do ciclo de vida de um produto pode auxiliar a gestão de resultados e estratégia de planejamento de vendas. Dessa forma, buscou-se realizar um estudo de caso de um comércio varejista 
Influência do ciclo de vida do produto em relação à classificação de clientes para planejar estratégias de venda: o caso de um comércio varejista de calçados e acessórios Wellington Pereira Godinho Neto, Rosângela Venâncio Nunes, CharlesWashington Costa de Assis, Rita de Cassia Fonseca, Nayana de Almeida Adriano

de calçados de moda e identificar as contribuições que a análise do ciclo de vida de um produto pode oferecer à gestão de resultados e estratégia de planejamento de vendas.

Dentre as várias aplicações do estudo do ciclo de vida do produto, destaca-se seu papel para que os gestores de moda possam diminuir a quantidade elevada de produtos fora de linha (coleções passadas) em estoque, obtendo, ao menos o retorno do valor investido.

O tema foi escolhido a partir da percepção de que, muitas empresas não aproveitam todo o potencial de seus produtos e, - também o notório prejuízo causado por manterem estoques cheios de produtos que se tornariam cada vez mais obsoletos $e$ com menor valor de mercado.

Para o desenvolvimento desta pesquisa, foi utilizada a pesquisa aplicada que, conforme Gil (2010), representa pesquisas voltadas à aquisição de conhecimento com vistas à aplicação em uma situação específica. - A pesquisa aplicada adota natureza qualitativa e caráter exploratório, com procedimentos de pesquisa bibliográfica, documental e estudo de caso. Utiliza-se a pesquisa bibliográfica e documental, com dados da empresa. O referencial teórico, sedimentado para execução da pesquisa, constitui-se de gestão de resultados e planejamento, além de análise do ciclo de vida do produto. Ao longo deste estudo, foram cumpridas as seguintes etapas para a sua realização: levantamento e seleção da literatura, realização dos distintos procedimentos da leitura analítica e dos que se referem à elaboração da pesquisa de campo, prevendo a incorporação destes dados no desenvolvimento do artigo.

Voltado à prática empresarial, esta pesquisa justifica-se pelo auxílio à empresa estudada, com a proposta do estudo do ciclo de vida dos produtos comercializados. Buscou-se uma contribuição para que a empresa possa planejar estratégias de venda para uma melhoria na sua gestão. 
Influência do ciclo de vida do produto em relação à classificação de clientes para planejar estratégias de venda: 0 caso de um comércio varejista de calçados e acessórios Wellington Pereira Godinho Neto, Rosângela Venâncio Nunes, CharlesWashington Costa de Assis, Rita de Cassia Fonseca, Nayana de Almeida Adriano

\section{REFERENCIAL TEÓRICO}

Para defender as bases teóricas deste trabalho, é importante levar em consideração os conceitos e premissas básicos relacionados com a gestão de resultados, planejamento e estratégia de vendas, análise do ciclo de vida do produto e suas aplicações. - A análise do ciclo de vida do produto pode auxiliar a gestão de resultados e a estratégia de planejamento de vendas.

\subsection{Gestão de resultados, planejamento e estratégia de vendas}

Ao se considerar a existência da relação entre Moda e Marketing, focam-se os quesitos mais importantes deste campo no que se refere à comercialização de produtos de moda. A necessidade deste enfoque deve-se ao fato de que o marketing voltado para o varejo de moda surge com o intuito de fazer uma ligação entre vários setores de uma empresa, prevenindo, assim, prejuízos e desordem.

Conforme SEBRAE (2013), em pesquisa realizada com empresas brasileiras constituídas em 2007, e suas informações disponíveis na SRF até 2010, a taxa de sobrevivência das empresas com até dois anos de atividade foi de $75,6 \%$. No mercado da moda, a probabilidade de um negócio pouco estruturado não ter continuidade é muito grande. Nesse contexto, vem-se trabalhando com o marketing para contornar maus resultados e prevenir-se com uma ideia positiva.

Um dos modelos de gestão que tem obtido maior sucesso entre empresas do segmento de varejo é o de resultados e planejamento, para se obter êxito nesse cenário, o comprometimento dos colaboradores está diretamente ligado ao escopo do trabalho, não necessariamente à carga ou horário desejado para a realização de uma determinada tarefa. Carvarantes, Panno e Kloeckner (2004, p. 85) dizem que há dois aspectos que se destacam sobre a gestão: o primeiro deles é a motivação, que é uma área crítica, visto que os colaboradores precisam estar engajados nas tarefas para alcançar os resultados esperados; e o segundo é o sistema e sua organização. A exigência para esse perfil de trabalho está baseada na agressividade para tomar 
Influência do ciclo de vida do produto em relação à classificação de clientes para planejar estratégias de venda: 0 caso de um comércio varejista de calçados e acessórios Wellington Pereira Godinho Neto, Rosângela Venâncio Nunes, CharlesWashington Costa de Assis, Rita de Cassia Fonseca, Nayana de Almeida Adriano

decisões, pró-atividade, dinamismo e determinação e comprometimento em realizar aquilo que se propôs através do trabalho em equipe.

Para liderar uma gestão baseada nos resultados e planejamento, é preciso um líder capaz de tomar decisões em equipe e conquistar seus objetivos através do empenho dela e da sua força de trabalho, muitas vezes subtraindo de seus colaboradores resultados que eles não conseguiriam no trabalho isolado, tendo como metas principais: dar direção; capacitar; motivar. Lenzi, Kiesel e Zucco (2010, p. 69), afirmam que, para uma organização alcançar o sucesso, é necessário que, acima de outros atributos, disponha de pessoas competentes em seu quadro de gestores e colaboradores.

Igualmente, quando se pensa em marketing e estratégias de vendas, percebe-se que uma das ferramentas mais utilizadas por empresas que alcançaram o sucesso são os 4 Ps do marketing: Produto, Preço, Praça e Promoção. Trigo (2010, p. 15) afirma que toda estratégia de marketing está baseada nos 4 Ps. Nesse sentido, é indispensável um breve comentário acerca de cada um desses elementos norteadores do marketing de forma mais ampla. O produto, ou serviço, é a base de qualquer negócio; para se dar início ao negócio, ele precisa estar bem definido. A partir desse ponto, será definido o preço, que estará diretamente ligado ao público-alvo, que também precisará ser analisado em conjunto com a praça em que o produto será ofertado. Por fim, será planejada a forma em que esse produto ou serviço será promovido para chegar ao cliente, chegando ao ponto de intercessão com o ciclo de vida do produto, uma vez que o objeto de estudo modifica o preço, a praça e a forma de promoção mediante o estágio em que o produto se encontra.

\subsection{Análise do ciclo de vida do produto e suas aplicações}

Quando se lança um produto, espera-se que ele dure muito tempo e que se possa lucrar bastante com ele. Contudo, é sabido que, em algum momento, as vendas desse produto começarão a se reduzir. Para Las Casas (2004, p. 175), o ciclo de vida de um produto começa desde o momento em que o produto é introduzido no mercado 
Influência do ciclo de vida do produto em relação à classificação de clientes para planejar estratégias de venda: o caso de um comércio varejista de calçados e acessórios Wellington Pereira Godinho Neto, Rosângela Venâncio Nunes, CharlesWashington Costa de Assis, Rita de Cassia Fonseca, Nayana de Almeida Adriano

até a sua retirada total. Ele passa pelos estágios da introdução, crescimento, maturidade e declínio.

E a moda é um dos setores onde o ciclo acontece de forma rápida, como afirma Cobra (2007, p. 26): "uma vez que seu ciclo de vida é curto, os produtos devem agilizar esforços para maximizar as vendas em um prazo também muito curto". Assim, torna-se obrigatório não simplesmente vender, mas, sim, encantar e seduzir as pessoas.

Sertek, Guindani e Martins (2009) afirmam que o ciclo de vida dos produtos foi baseado na biologia e no ciclo de vida dos seres vivos, de acordo com a Figura 1.

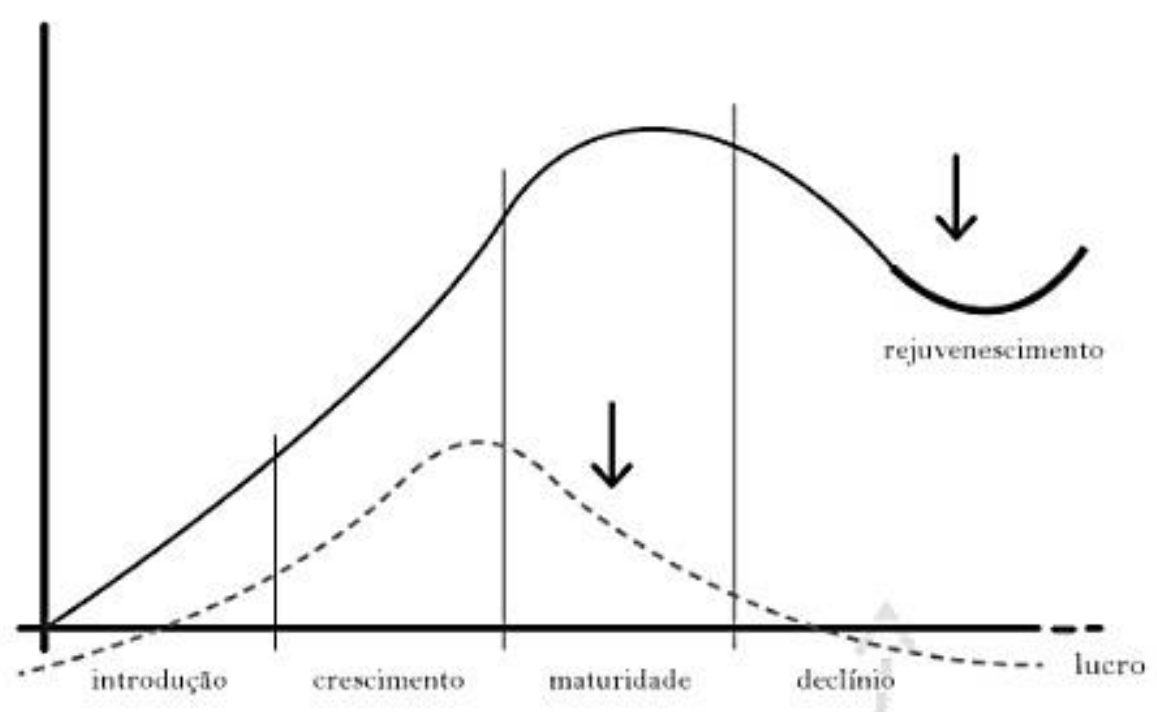

Figura 1 - Ciclo de vida do produto

Fonte: (SERTEK; GUINDANI; MARTINS, 2009, p. 71).

De acordo com Kotler e Keller (2006), esse ciclo compreende desde o momento embrionário do produto até a fase final de sua exploração econômica e pode ser evidenciado por quatro estágios:

- Introdução: período em que há o lançamento do produto. Em alguns setores do mercado, esse período gera pouco ou nenhum lucro, e o crescimento é lento, por conta dos custos que houve para sua colocação no mercado. No objeto de estudo, isso se dá de forma muito rápida, visto 
Influência do ciclo de vida do produto em relação à classificação de clientes para planejar estratégias de venda: o caso de um comércio varejista de calçados e acessórios Wellington Pereira Godinho Neto, Rosângela Venâncio Nunes, CharlesWashington Costa de Assis, Rita de Cassia Fonseca, Nayana de Almeida Adriano

que a expectativa pela nova coleção é enorme, passando rapidamente pela aceitação.

- Crescimento: onde há a aceitação no mercado e os lucros são crescentes. Constitui a maior fase de venda do ciclo de um produto de moda, gerando alta lucratividade.

- Maturidade: baixo crescimento de vendas. Os lucros diminuem ou tornamse estáveis. Nesta fase, existe a necessidade de "defender" seu produto em relação à concorrência.

- Declínio: vendas e lucros começam a cair. Final de coleção e se começa a colocar em prática as ideias para liquidar o estoque na própria loja e, posteriormente, repassando a outras lojas dos grupos, se assim possuir.

Para determinar onde cada estágio começa e termina, é necessário ficar atento aos detalhes que as vendas e os lucros transmitem. O Quadro 1, a seguir, representa um resumo sobre essa análise.

\begin{tabular}{|c|c|c|c|}
\hline \multirow{2}{*}{ Clico de Vida } & Vendas & Custos & \multirow{2}{*}{ Lucros } \\
\hline \multirow{2}{*}{ Introdução } & Crescimento & Altos - em virtude do lança- & Inexistem ou são \\
\cline { 2 - 3 } & lento & mento do produto. & negativos \\
\hline \multirow{2}{*}{ Crescimento } & Crescimento & Reduzidos - em função da & \multirow{2}{*}{ Altos } \\
\cline { 2 - 3 } & significativo & produção em escala. & \multirow{2}{*}{ Manutenção ou } \\
\hline \multirow{2}{*}{ Maturidade } & Estabilização & Altos - decorrentes de & declínio \\
\cline { 2 - 3 } & ou queda & investimentos em marketing. & \\
\hline \multirow{2}{*}{ Declínio } & \multirow{3}{*}{ Forte queda } & Estabilizam - em função da & \multirow{2}{*}{ Desaparecem } \\
\cline { 3 - 3 } & & diminuição da produção em & \\
\cline { 3 - 3 } & & escala compensada pela & \\
\cline { 3 - 3 } & & redução de investimentos & \\
\cline { 3 - 3 } & & em marketing. & \\
\hline
\end{tabular}

Quadro 1 - Ciclo de Vida do Produto e seus efeitos no lucro

Fonte: Adaptado de KOTLER; KELLER 2006. 
Influência do ciclo de vida do produto em relação à classificação de clientes para planejar estratégias de venda: o caso de um comércio varejista de calçados e acessórios Wellington Pereira Godinho Neto, Rosângela Venâncio Nunes, CharlesWashington Costa de Assis, Rita de Cassia Fonseca, Nayana de Almeida Adriano

Assim, conclui-se que a divisão entre os estágios é delicada, e torna-se ainda mais complexa quando há um mix de produtos bastante variado. É necessária uma atenção especial às oscilações do mercado onde se está inserido, observando o surgimento dos lucros no período de introdução, seu aumento durante o crescimento, sua estabilização na maturidade e, principalmente, sua queda no seu declínio. Com iss, pode-se analisar sua interferência na gestão de resultados e estratégia de planejamento de vendas.

\subsection{Ciclo de vida do produto como ferramenta para gestão de resultados e estratégia de planejamento de vendas.}

A gestão de resultados, assim como a estratégia de planejamento de vendas sofre alto nível de interferência do ciclo de vida do produto, em função dos lucros e do tempo que o produto estará à venda. Isso depende do tempo do seu ciclo de vida, enquanto o aproveitamento dos altos índices de lucro no estágio de crescimento está diretamente ligado à forma como esse produto será levado até seu mercado-alvo, por meio da promoção.

Para Nunes (2015), a gestão por resultados se baseia no estabelecimento de resultados esperados para o futuro a partir das formas de estratégias, baseando-se nos objetivos que se quer atingir.

Dessa forma, a gestão por resultados se opõe à gestão burocrática, pois esta enfatiza os processos e sistemas de controle, enquanto a gestão por resultados tem seu foco nos resultados que quer atingir.

\section{METODOLOGIA}

A base da metodologia é a pesquisa, o levantamento de informações para chegar à resolução de problemas e questionamentos. Segundo Silva e Menezes (2001), insere a pesquisa como uma atividade desempenhada no dia a dia, um "questionamento sistemático crítico e criativo, mais a intervenção competente na 
Influência do ciclo de vida do produto em relação à classificação de clientes para planejar estratégias de venda: o caso de um comércio varejista de calçados e acessórios Wellington Pereira Godinho Neto, Rosângela Venâncio Nunes, CharlesWashington Costa de Assis, Rita de Cassia Fonseca, Nayana de Almeida Adriano

realidade, ou o diálogo crítico permanente com a realidade em sentido teórico e prático".

A pesquisa é a realização do estudo planejado, sendo que o método de abordagem do problema é o que a caracteriza. De acordo Souza, Santos e Dias (2013, p. 59), "a pesquisa científica é o conjunto de procedimentos sistemáticos, baseado no raciocínio lógico, que tem por objetivo encontrar soluções para os problemas propostos, mediante o emprego de métodos científicos". A pesquisa sempre parte de um problema, algo que ainda não foi respondido, e o conhecimento ainda não foi capaz de resolvê-lo. Souza, Santos e Dias (2013, p. 61) conceituam a pesquisa como um "processo formal e sistemático de desenvolvimento do método científico", tendo como objetivo principal obter respostas para os problemas propostos com o uso de procedimentos científicos. Para alcançar tais respostas, é necessário entender também o objeto de estudo.

\subsection{Objeto de Estudo}

O objeto de estudo é o grupo Meia Sola Acessórios de Moda, grupo cearense inserido no mercado de moda há 28 anos, sendo uma das empresas mais conceituadas do setor, pois ganhou prêmios de administração e foi considerada pela marca Arezzo, por vários anos, sua melhor franquia.

Para alcançar as respostas pretendidas, foi preciso, primeiramente, coletar os dados necessários para o estudo e, posteriormente, analisá-los.

\subsection{Procedimento de Coleta de Dados}

Nesse estudo, realizou-se uma pesquisa aplicada, em material bibliográfico, artigos que abordaram o assunto e observações realizadas dentro do objeto de estudo, objetivando agregar conhecimentos práticos à solução de problemas específicos, com abordagem qualitativa. Para alcançar os objetivos propostos, a pesquisa será de caráter exploratório, tendo como procedimentos técnicos os adotados para a pesquisa bibliográfica, documental e estudo de caso. 
Influência do ciclo de vida do produto em relação à classificação de clientes para planejar estratégias de venda: o caso de um comércio varejista de calçados e acessórios Wellington Pereira Godinho Neto, Rosângela Venâncio Nunes, CharlesWashington Costa de Assis, Rita de Cassia Fonseca, Nayana de Almeida Adriano

Neste sentido, foram coletados dados para a realização do estudo de caso a partir de conversas com gestores e dos relatórios gerenciais da empresa, que expressavam informações sobre os clientes e seus produtos. Entre os dados coletados, no que tange aos clientes, destacam-se: relação e classificação de clientes por loja, margem de lucro por cliente, nível de faturamento. No que se refere aos produtos, foram coletados os seguintes dados: faturamento, custos, tempo de estocagem até a venda, volume de venda, margem de lucro.

Vale salientar que, por questão de sigilo empresarial, os valores de produtos não puderam ser divulgados neste artigo; somente podem ser apresentados de forma comparativa em classificações. Como dito anteriormente, após a coleta de dados, o procedimento seguinte é o de análise do material pesquisado.

\subsection{Procedimentos de Análise de Dados}

Obedecendo ao planejamento da pesquisa, o primeiro passo foi definir o tema e sua delimitação, para construir um plano de pesquisa e iniciar sua execução. Após todo o levantamento de dados e constatação de fatos observados, o último passo foi redigir e organizar as ideias para o relatório final e a conclusão dos objetivos predeterminados.

Foi realizada uma pesquisa aplicada de natureza qualitativa, com caráter exploratório, com procedimentos de pesquisa bibliográfica, documental e estudo de caso. A pesquisa foi aplicada conforme sua natureza, que, segundo Gil (2010) representa a aquisição de conhecimento com vistas à aplicação - da pesquisa - em uma situação específica.

Os dados coletados que se referiram aos clientes como produtos, discriminados no item anterior, receberam tratamento de classificação por fase do ciclo de vida do produto bem como tratamento de apresentação das análises através de quadros e gráficos. 
Influência do ciclo de vida do produto em relação à classificação de clientes para planejar estratégias de venda: 0 caso de um comércio varejista de calçados e acessórios Wellington Pereira Godinho Neto, Rosângela Venâncio Nunes, CharlesWashington Costa de Assis, Rita de Cassia Fonseca, Nayana de Almeida Adriano

\section{ESTUDO DE CASO}

O presente estudo de caso utiliza a empresa do ramo de calçados e acessórios, Meia Sola, para atingir o objetivo de demonstrar como a análise do ciclo de vida do produto pode auxiliar na classificação de clientes, a fim de gerar mais lucros e diminuir os desperdícios e prejuízos com a manutenção de estoques indesejáveis e planejar melhor as estratégias de vendas.

\subsection{O ambiente de estudo - Meia Sola Acessórios de Moda Ltda.}

A entidade estudada atua no ramo varejista de acessórios de moda. É uma empresa familiar, que atua no mercado desde a década de 1980; possui 22 lojas e, atualmente, conta com 300 colaboradores em seu quadro de funcionários. Tem sua matriz sediada em Fortaleza, possuindo lojas também na região metropolitana e no interior do Estado do Ceará.

O grupo Meia Sola foi fundado em 1ำ de março de 1986. Hoje, é líder no mercado cearense para os públicos A e B. Além das quatro lojas que levam o nome do grupo, ainda possuem diversas franquias: nove lojas Arezzo, três lojas Schutz, uma loja Ana Capri, três lojas L'Occitane (atuante no setor de cosméticos) e duas lojas voltadas às classes $\mathrm{C}$ e $\mathrm{D}$, a Pop Club.

A missão da empresa é "manter-se referência nacional no lançamento da moda, superando as expectativas de nossos clientes, colaboradores acionistas e da sociedade, profissionalizando as pessoas, ampliando e mantendo a solidez nos negócios, com honestidade e ética, e oferecendo produtos exclusivos e de qualidade, com excelência em serviços". Sua visão é "lançar moda, vendendo produtos exclusivos de qualidade, oferecendo excelência em serviços, gerando clientes e colaboradores fiéis e felizes".

O grupo não possui indústria; compra e revende suas mercadorias em franquias e lojas multimarcas. Com isso, o primeiro estágio, o de desenvolvimento do produto, é diferente em relação às indústrias, que fazem estudos para a idealização de novos produtos. Assim sendo, o importante desse estágio é o estudo das tendências da nova 
Influência do ciclo de vida do produto em relação à classificação de clientes para planejar estratégias de venda: 0 caso de um comércio varejista de calçados e acessórios Wellington Pereira Godinho Neto, Rosângela Venâncio Nunes, CharlesWashington Costa de Assis, Rita de Cassia Fonseca, Nayana de Almeida Adriano

coleção e quais produtos estarão melhor alinhados ao mercado consumidor local, visto que as marcas que representam possuem suas fábricas e linhas de produção no sul e sudeste do país.

No mercado onde está inserida, a Meia Sola possui exclusividade sobre as marcas representadas; sendo assim, apenas o grupo pode revendê-las onde possuir lojas, dispondo de uma variedade maior que os concorrentes do setor de bolsas e calçados, além de produtos já aceitos e supervalorizados pelas classes $A$ e $B$, o que já é uma estratégia de vendas da empresa. A seguir veremos detalhes sobre 0 planejamento e mais estratégias.

\subsection{Planejamento e estratégias de vendas utilizadas pela empresa}

O planejamento anual sobre as metas de cada loja é a principal atuação na gestão de resultados da empresa. O levantamento mês a mês das vendas obtidas e das metas alcançadas, ou não, do ano anterior é a base para a projeção, levando-se em conta também o apurado de todo o setor de acessórios de moda.

Missão e visão também são consideradas na elaboração das estratégias e do planejamento, definindo o negócio da empresa e a posição almejada. A seguir, vem a segmentação de clientes, utilizada para o planejamento de vendas, pois sabendo classificar o público-alvo obtêm-se melhores resultados, promovendo melhores campanhas de marketing e estratégias de precificação.

\subsubsection{Classificação de Clientes}

A classificação dos clientes é feita pela empresa, seguindo-se as classes sociais, clientes A, B, C e D.

Os clientes A são mais específicos e se concentram mais nas lojas Meia Sola Multimarcas e Schutz, cujos produtos vendidos são sofisticados e exclusivos, além de possuírem maior diferencial, incluindo o valor precificado e também o agregado. Tem, em sua maioria, mulheres de classe $A$, entre 20 e 60 anos, que acompanham as últimas tendências de moda. Suas lojas estão localizadas em pontos estratégicos, ou seja, 
Influência do ciclo de vida do produto em relação à classificação de clientes para planejar estratégias de venda: o caso de um comércio varejista de calçados e acessórios Wellington Pereira Godinho Neto, Rosângela Venâncio Nunes, CharlesWashington Costa de Assis, Rita de Cassia Fonseca, Nayana de Almeida Adriano

bairros nobres da cidade de Fortaleza, que as clientes costumam frequentar e que, muitas vezes, moram nos arredores.

Os clientes B também exigem exclusividade; no entanto, os produtos para os quais possuem maior poder de compra não possuem tanto apelo sobre o status. Estes possuem preços mais atrativos, alcançando mercados e clientes da classe C, diferenciando inclusive a praça onde ofertam seus produtos, possuindo lojas no centro da cidade, North Shopping, Via Sul Shopping e interior do estado.

A classe $\mathrm{C}$ é a que mais cresce. Nos últimos anos, o perfil do Brasil está mudando. De 2002 a 2012, a Classe Média brasileira ganhou 37 milhões de novos participantes, pessoas que deixaram de apenas sobreviver para se tornarem consumidores (LORENZO, 2013). Com o seu poder de compra maior, esses clientes já possuem número de compras consideráveis nas lojas às quais antes apenas os clientes B tinham acesso; por isso, o grupo abriu lojas onde esse público possui maior acesso.

A Classe $D$ também está tendo acesso aos produtos que antes apenas os clientes A e B possuíam com a abertura da loja Pop Club, que vende produtos de coleções anteriores, justamente para que o valor agregado almejado pelas classes mais elevadas não diminua.

Com a abertura da loja para um novo segmento de clientes, o grupo descobriu como remoçar o ciclo de vida de seus produtos. Quando os produtos atingem o estágio de declínio e não possuem mais vendas satisfatórias, mesmo em período de liquidações, ele é remanejado para essa loja e lá se torna um lançamento para os clientes $C$ e $D$, que não deixam de procurar produtos de valor mais acessível. O Quadro 2 demonstra um mapeamento realizado com base nas informações cedidas pela empresa para melhor entendimento da classificação dos clientes-alvo de cada loja do grupo Meia Sola.

\begin{tabular}{|c|c|c|c|}
\hline CLIENTE A & CLIENTE B & CLIENTE C & CLIENTE D \\
\hline Lojas Meia Sola e Schutz & Loja Arezzo & Lojas Arezzo e Pop Club & Loja Pop club \\
\hline
\end{tabular}

Quadro 2 - Segmento de cliente por loja do grupo Meia Sola Fonte: Elaborado pelos autores. 
Influência do ciclo de vida do produto em relação à classificação de clientes para planejar estratégias de venda: o caso de um comércio varejista de calçados e acessórios Wellington Pereira Godinho Neto, Rosângela Venâncio Nunes, CharlesWashington Costa de Assis, Rita de Cassia Fonseca, Nayana de Almeida Adriano

Ao observar o Quadro 2, percebe-se que cada loja possui como alvo clientes de classes distintas. Esta compreensão é relevante para o planejamento de vendas e gestão de resultados, pois, entendendo-se qual é o cliente-alvo de cada loja, verificamse quais as contribuições de cada produto e cada cliente no decorrer do seu ciclo de vida.

A classificação dos clientes possui expressividade para planejamento da empresa; trata-se de um conceito simples, mas que não é trivial. O fato é que, mesmo comercializando produtos, todas as organizações estão envolvidas nos serviços ao cliente e em sua percepção de valor.

Por meio da metodologia de classificação de clientes, a gestão pode avaliar o impacto econômico de cada classe de cliente, pois os custos associados a cada um deles para atendimento ao produto e nível de serviço requerido não estão necessariamente e diretamente correlacionados ao volume de vendas. Podem existir clientes que compram baixo volume, mas que demandam grande esforço logístico e mercadológico. O planejamento de vendas pode ser estabelecido não apenas em função das necessidades dos clientes, mas também em função da rentabilidade que estes podem propiciar à organização.

Assim conclui-se que a organização possui diversos clientes que geram diversos níveis de resultados econômicos para a empresa. É necessário selecionar clientes e seus perfis para melhor atendê-los, verificando-se quanto valem para a empresa em termos de atratividade.

\subsubsection{Análise do ciclo de vida do produto e suas contribuições no planejamento e nas estratégias de vendas para gestão de resultados}

O ciclo de vida dos produtos vendidos pelo grupo Meia Sola está diretamente ligado ao sucesso de vendas. É preciso, por parte da organização, um estudo apurado sobre o "tempo de vida" de cada um deles. Como já apontado, são quatro fases do ciclo de vida dos produtos, e a empresa analisa cada produto separadamente, embora no setor varejista de moda ele tenha um tempo total generalizado à coleção em que aquele 
Influência do ciclo de vida do produto em relação à classificação de clientes para planejar estratégias de venda: 0 caso de um comércio varejista de calçados e acessórios Wellington Pereira Godinho Neto, Rosângela Venâncio Nunes, CharlesWashington Costa de Assis, Rita de Cassia Fonseca, Nayana de Almeida Adriano

produto está inserido, pois, quando há troca de coleção, praticamente todos os produtos da coleção anterior já estão na fase final de seu ciclo.

O ciclo de cada produto tem duração média de doze meses, correspondendo aos seis meses de desenvolvimento, que duram enquanto a coleção anterior está no mercado, e os outros seis meses distribuídos nos outros quatro estágios do ciclo de vida.

Os produtos da empresa são variados: bolsas e calçados variados são os principais produtos ofertados, mas o mix também pode incluir, dependendo da coleção, colares, brincos, esmaltes e outros acessórios de moda. Para o estudo, a análise foi realizada no produto bolsa, da marca Luz da Lua, e uma sapatilha da marca Schutz, pois, segundo análises já realizadas pela empresa, são produtos com bastante procura a cada início de uma nova coleção, obtendo rápida aceitação e se encaixando na interseção entre o final de um ciclo para um segmento de clientes e o início para outro.

O período de introdução se dá quando as marcas vendidas lançam seus produtos em novas coleções e há a compra. Nesse estágio, o retorno do investimento é o principal objetivo, buscando cobrir os custos da aquisição da nova coleção.

As classes sociais A e B, público-alvo da empresa analisada, possuem em suas características a necessidade de possuir o bem antes que esse se "popularize". A consequência disso, no ciclo de vida, é um rápido crescimento nas vendas após a introdução dos produtos no mercado. Esse estágio é conhecido como crescimento e é a maior etapa de venda do produto, gerando alta lucratividade.

Após a crescente de vendas, a tendência é que haja uma estabilização nesses números; claro que durante os ciclos existem momentos especiais que não podem virar regra, como datas comemorativas, em que as vendas crescem independentemente da etapa e da coleção do momento. A esse estágio se dá o nome de maturidade, em que o lucro tende a se manter estável.

Em último estágio, observa-se um ponto chave no ciclo de vida: o que fazer quando o produto chega ao declínio. E são em ideias inovadoras que o grupo Meia Sola se destaca. Há três anos, abriram uma loja, a Pop Club, para que esses produtos em 
Influência do ciclo de vida do produto em relação à classificação de clientes para planejar estratégias de venda: o caso de um comércio varejista de calçados e acessórios Wellington Pereira Godinho Neto, Rosângela Venâncio Nunes, CharlesWashington Costa de Assis, Rita de Cassia Fonseca, Nayana de Almeida Adriano

final de coleção e de coleções anteriores fossem remanejados. Assim, o momento de declínio no mercado das classes $A$ e $B$ é o de introdução para as classes $C$ e $D$, com preços mais atrativos, que atingem o novo objetivo, conforme exemplificado na Figura 2.

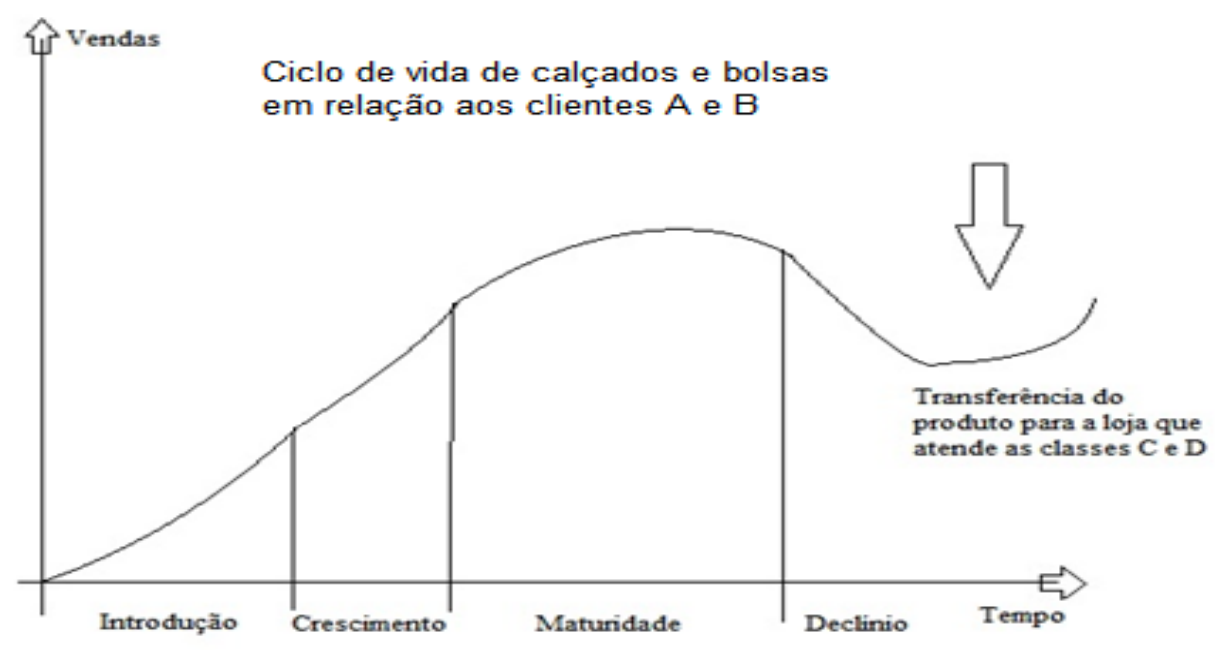

Figura 2 - Ciclo de vida de calçados e bolsas em relação aos clientes A e B Fonte: Elaborado pelo pelos autores (2014).

Observa-se, então, que a gestão de resultados e planejamento e de estratégias de vendas estão diretamente ligadas ao ciclo de vida do produto. De acordo com o estágio e o público-alvo ao qual está direcionada, a empresa pode tomar decisões diversas. No tema estudado, a realocação das mercadorias fora de coleção faz com que o lucro, antes decadente, volte a ter uma curva ascendente, mesmo que em menor valor, visto que, para atingir as classes mais baixas, o valor de venda precisa está de acordo.

A seguir, na Figura 3, apresenta-se o ciclo de vida de uma sandália multimarca, em que o período de introdução é breve, visto que a expectativa e ansiedade por parte dos consumidores são enormes, fazendo com que a nova coleção e os novos produtos sejam aceitos rapidamente. 
Influência do ciclo de vida do produto em relação à classificação de clientes para planejar estratégias de venda: o caso de um comércio varejista de calçados e acessórios Wellington Pereira Godinho Neto, Rosângela Venâncio Nunes, CharlesWashington Costa de Assis, Rita de Cassia Fonseca, Nayana de Almeida Adriano

O crescimento é o período mais longo do ciclo, assim como o crescimento do lucro é diretamente proporcional. A maturidade é atingida próximo ao final do ciclo de vida do produto, mas, embora estável, ainda há lucro considerável nessa fase. 0 declínio também é uma etapa pequena. Nessa fase, são realizadas as liquidações para a liberação de estoque para a próxima coleção que já está próxima à introdução.

Após as liquidações, os produtos ainda remanescentes são deslocados para a loja do grupo que atende às classes $\mathrm{C}$ e $\mathrm{D}$. Esses produtos são transferidos de forma gradual, para não haver uma super oferta e o valor diminuir ainda mais. Embora o lucro seja reduzido, ele ainda existe.

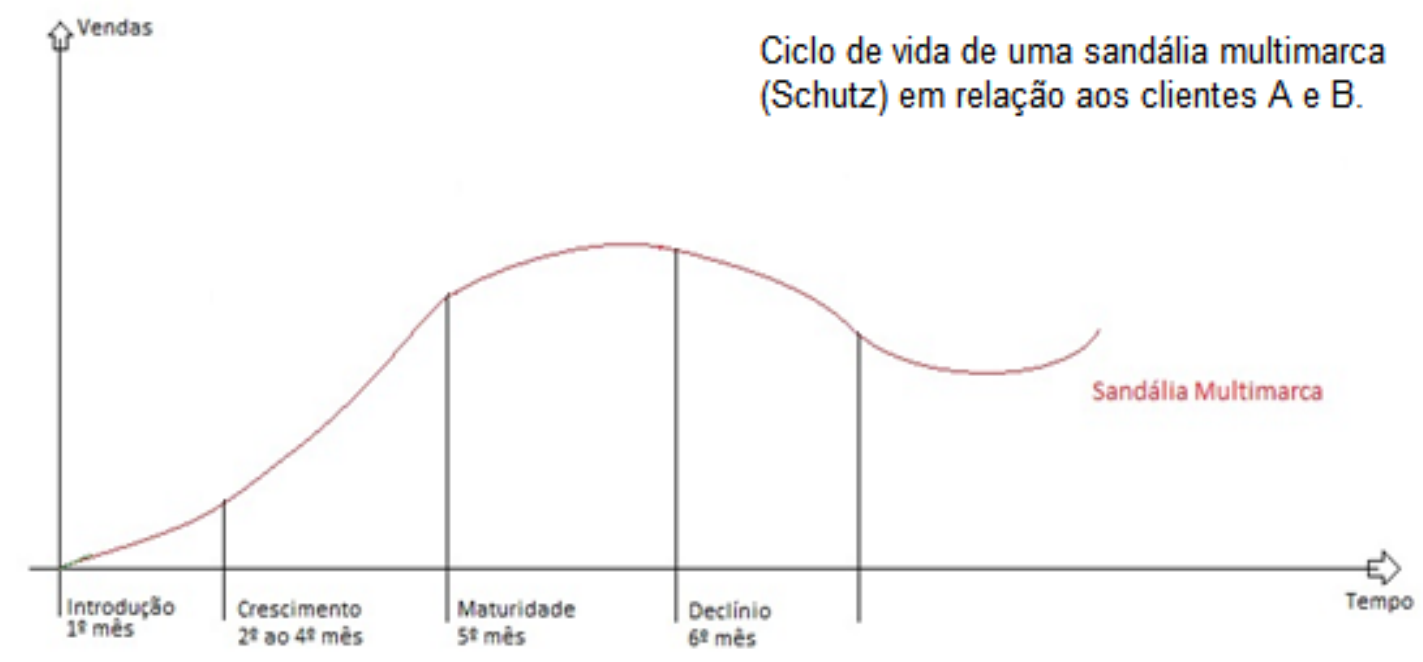

Figura 3 - Ciclo de vida de uma sandália multimarca (Schutz) em relação aos clientes A e B Fonte: Elaborado pelos autores (2014).

Após o produto ser remanejado para a loja Pop Club, que atende ao público $\mathrm{C} \mathrm{e}$ D, o ciclo volta ao início, passando pelo período introdutório até o declínio, conforme a Figura 4. 
Influência do ciclo de vida do produto em relação à classificação de clientes para planejar estratégias de venda: 0 caso de um comércio varejista de calçados e acessórios Wellington Pereira Godinho Neto, Rosângela Venâncio Nunes, CharlesWashington Costa de Assis, Rita de Cassia Fonseca, Nayana de Almeida Adriano

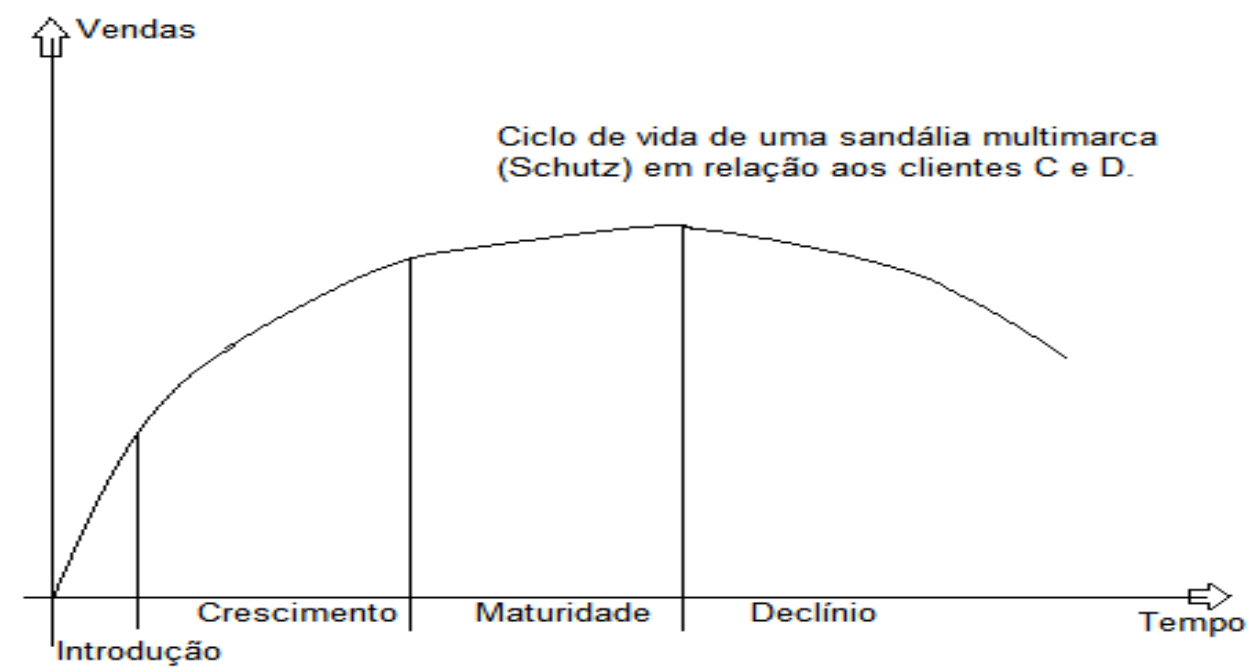

Figura 4 - Ciclo de vida de uma sandália multimarca (Schutz) em relação aos clientes C e D Fonte: Elaborado pelos autores (2014).

Em relação a esses clientes, o período de introdução é bem menor, visto que o valor do investimento já foi recuperado quando o calçado estava no ciclo dos produtos em relação aos clientes $A$ e $B$, passando rapidamente para o crescimento, onde 0 produto é rapidamente aceito pelas classes $C$ e $D$, que buscam comprar os mesmos itens que as classes $A$ e $B$ possuem, mesmo sem se importar se são mercadorias de coleções anteriores. Quando chegam ao estágio do declínio, esses produtos, por serem de numerações de "sobras de coleção", são doados para que não voltem a ocupar estoque, valendo também para agregar à marca o valor social.

Quando se analisa o ciclo de vida de uma bolsa multimarca, percebe-se uma diferença em relação ao maior percentual de vendas em relação às sandálias. Outro fator determinante: o período em que permanece no estágio de maturidade e declínio é maior, pois, devido à menor quantidade de modelos e produtos, ao saírem do estágio de crescimento, há uma redução maior do número de vendas do que em relação aos calçados; no entanto, por possuírem preços de venda também mais elevados, o lucro tem apenas uma leve queda. Durante a fase de declínio, essa bolsa pode permanecer no estoque por mais de uma liquidação, chegando a ter lucro zero durante a introdução, 
Influência do ciclo de vida do produto em relação à classificação de clientes para planejar estratégias de venda: 0 caso de um comércio varejista de calçados e acessórios Wellington Pereira Godinho Neto, Rosângela Venâncio Nunes, CharlesWashington Costa de Assis, Rita de Cassia Fonseca, Nayana de Almeida Adriano

crescimento e maturidade da coleção seguinte, retardando, assim, sua transferência para a loja mais popular da marca, como se vê na Figura 5 a seguir.

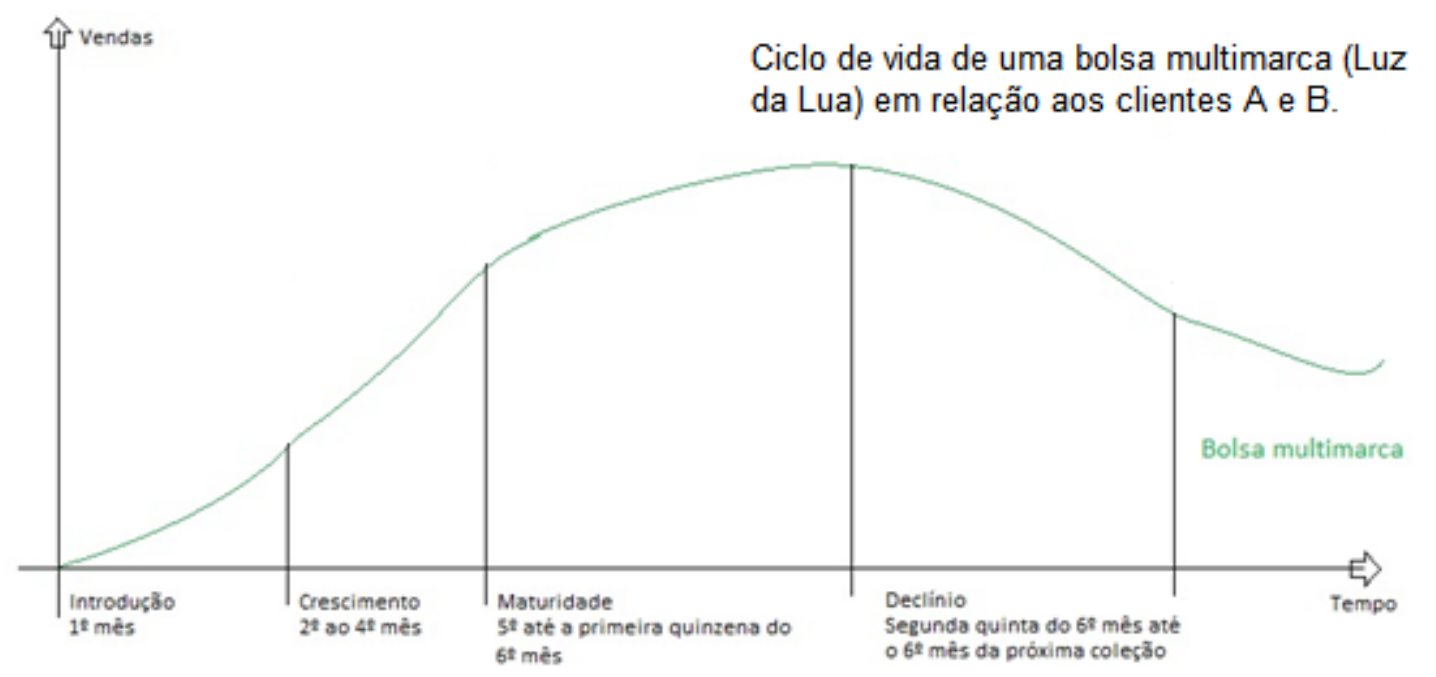

Figura 5 - Ciclo de vida de uma bolsa multimarca (Luz da Lua) em relação aos clientes A e B Fonte: Elaborado pelos autores (2014).

Pelo exposto, conclui-se que a análise do ciclo de vida do produto, em relação à empresa estudada, está diretamente ligada à maior obtenção de lucro possível com o mesmo produto aproveitando-se tudo o que se pode oferecer em uma loja e ao tipo de cliente; posteriormente, é transferido para outra loja, voltando-se a lucrar com outro público-alvo. Vale observar que os postos-chave de mudança entre um estágio e outro são as tomadas de decisões, mediante a gestão de resultados, para que a marca não sofra com a redução no volume de vendas.

Quando se observa a mesma bolsa em relação aos clientes C e D, percebe-se uma semelhança entre o calçado analisado para a mesma classe social, como se exemplificará na Figura 6. 
Influência do ciclo de vida do produto em relação à classificação de clientes para planejar estratégias de venda: o caso de um comércio varejista de calçados e acessórios Wellington Pereira Godinho Neto, Rosângela Venâncio Nunes, CharlesWashington Costa de Assis, Rita de Cassia Fonseca, Nayana de Almeida Adriano

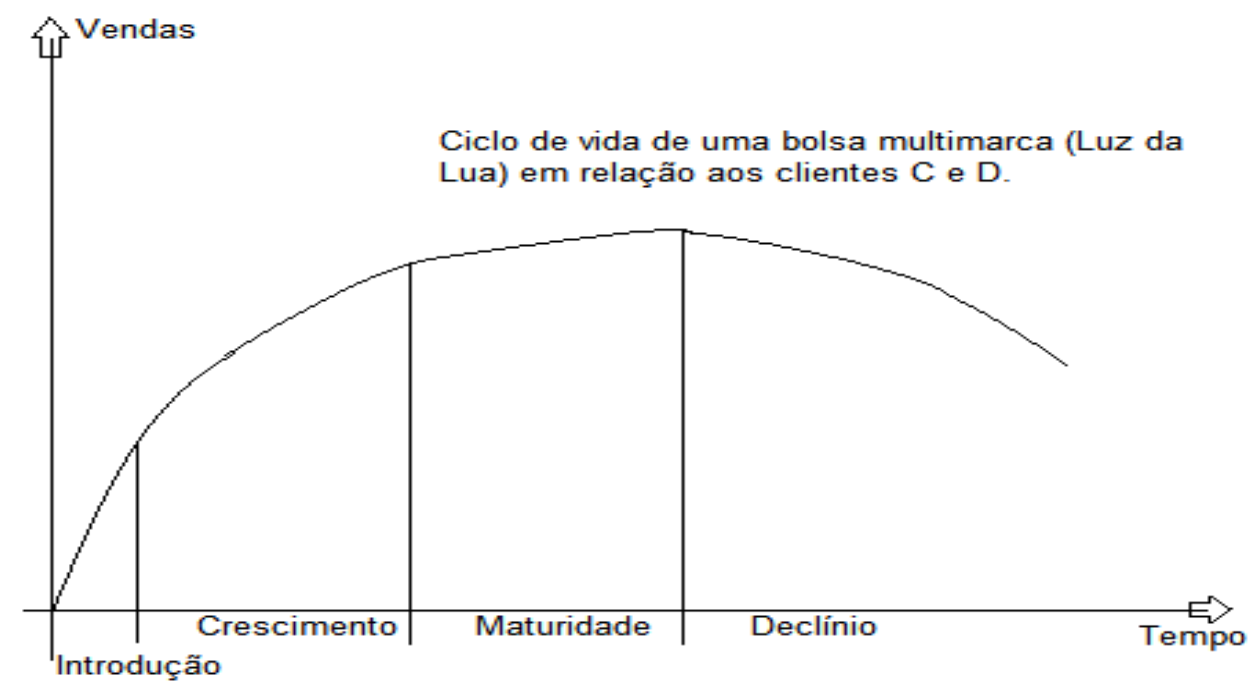

Figura 6 - Ciclo de vida de uma bolsa multimarca (Luz da Lua) em relação aos clientes C e D Fonte: Elaborado pelos autores (2014).

Como no primeiro ciclo, a loja possui a bolsa em menor quantidade em ralação ao calçado; por isso, quando analisamos as vendas em percentuais, ela se torna maior, mas, nesse estado, sua quantidade torna-se tão pequena que o percentual de lucro chega a se igualar.

Para entender melhor a relação entre os produtos e o lucro, acompanhe o Quadro 3 a seguir.

\begin{tabular}{|c|c|c|c|}
\hline PRODUTO & PREÇO DE VENDA & CUSTO & LUCRO \\
\hline Sand. Schutz & Mediano & Mediano & Menor \\
\hline Bolsa Luz da Lua & Maior & Maior & Mediano \\
\hline Sand. Arezzo & Menor & Menor & Maior \\
\hline
\end{tabular}

Quadro 3 - Relação preço de venda x custo x lucro Fonte: Elaborado pelos autores (2014).

Em virtude do sigilo em relação aos valores de custo e de venda, a análise tem que ser feita apenas com comparação entre o maior custo e a maior venda; analisandose percentualmente o maior lucro, conclui-se que a sandália Arezzo, que possui o 
Influência do ciclo de vida do produto em relação à classificação de clientes para planejar estratégias de venda: o caso de um comércio varejista de calçados e acessórios Wellington Pereira Godinho Neto, Rosângela Venâncio Nunes, CharlesWashington Costa de Assis, Rita de Cassia Fonseca, Nayana de Almeida Adriano

menor preço de custo, obtém o maior lucro percentual. Esse produto destina-se aos clientes B e a alguns clientes $\mathrm{C}$. O menor lucro em percentual, mas apenas um pouco menor que a bolsa, é a sandália Schutz, que possui o preço de custo e de venda medianos, enquanto a bolsa Luz da Lua possui o maior preço de custo e o maior preço de venda, mas, em percentual, não possui o lucro tão elevado, embora seu valor precificado seja o maior.

Assim, em relação ao grupo Meia Sola, observa-se que a classificação de clientes e a análise do ciclo de vida do produto contribuem no planejamento de estratégias de vendas e na obtenção de resultados, pois ajuda a empresa a tomar decisões sobre quais produtos irão adquirir, de acordo com o mercado-alvo para venda, quais os preços que irão praticar as lojas às quais esses produtos se destinarão e a forma como irão atingir esses clientes em termos de propaganda, além de se ter controle sobre o momento certo de tirar tais produtos de circulação e encaminhá-los às demais lojas que terão melhor aceitação no sentido de estender seu ciclo de vida.

\section{DISCUSSÕES}

Com base nos resultados da pesquisa realizada, percebe-se que, para a obtenção de retorno e sucesso no empreendimento, é necessária uma pesquisa de mercado detalhada, para que o empreendedor possa decidir com que produto trabalhará e para qual público-alvo o ofertará, observando evidentemente, a demanda e concorrentes para esse produto que será inserido no mercado, além de realizar a segmentação de mercado adequada.

Ao se refletir sobre os resultados verificados nos estudos já realizados e na teoria sobre o tema, observa-se que os resultados desta pesquisa confirmam a teoria e apresentam condições de contorno para entendê-la, visto que, a pesquisa confirmou a teoria de que a análise do ciclo de vida representa uma das peças-chave para aumentar os lucros na organização, pois um planejamento que desconsidere esta ferramenta, bem como a falta de atenção aos indicadores, podem fazer com que seus 
Influência do ciclo de vida do produto em relação à classificação de clientes para planejar estratégias de venda: o caso de um comércio varejista de calçados e acessórios Wellington Pereira Godinho Neto, Rosângela Venâncio Nunes, CharlesWashington Costa de Assis, Rita de Cassia Fonseca, Nayana de Almeida Adriano

produtos de moda tornem-se obsoletos e os concorrentes ganhem o espaço de mercado que antes lhe pertencia.

Assim, os resultados da pesquisa realizada confirmam a teoria de que a análise do ciclo de vida do produto e a classificação de clientes são ferramentas essenciais para que os gestores possam realizar o planejamento correto para traçar as estratégias de vendas da empresa e, assim, tornar o processo decisório mais eficiente, atingindo os resultados esperados e viabilizando os investimentos realizados.

\section{CONCLUSÕES}

A classificação de clientes e a análise do ciclo de vida do produto mostraram-se neste estudo como ferramentas pertinentes para que a organização possa obter resultados econômicos e gerir oportunidades. Verificou-se no estudo que tanto a classificação dos clientes como a análise do ciclo de vida do produto podem oferecer à gestão informações para melhor avaliar o impacto econômico de cada classe-cliente.

Observaram-se, por meio do estudo de caso, que a organização estudada possui diversos clientes e necessita gerir diversos níveis de resultados econômicos para a empresa. Logo, é necessário selecionar clientes e seus perfis, para melhor atendê-los, verificando quanto valem para a empresa em termos de atratividade. Dentre as várias aplicações do estudo do ciclo de vida do produto, destaca-se seu papel para que os gestores de moda possam diminuir a quantidade elevada de produtos fora de linha (coleções passadas) em estoque, obtendo, ao menos, o retorno do valor investido.

Dessa maneira, observou-se a contribuição que a análise do ciclo de vida do produto e a classificação de clientes oferecem para planejamento de estratégias de venda na busca da melhoria de resultados em um comércio varejista de calçados e acessórios.

O presente estudo discorreu sobre gestão de resultados e estratégias de planejamento de vendas; conceituou a análise do ciclo de vida de um produto e apresenta suas aplicações; identificou como a análise do ciclo de vida de um produto 
Influência do ciclo de vida do produto em relação à classificação de clientes para planejar estratégias de venda: o caso de um comércio varejista de calçados e acessórios Wellington Pereira Godinho Neto, Rosângela Venâncio Nunes, CharlesWashington Costa de Assis, Rita de Cassia Fonseca, Nayana de Almeida Adriano

pode auxiliar a gestão de resultados e estratégia de planejamento de vendas; e realizou um estudo de caso de um comércio varejista de calçados de moda a identificar as contribuições que a análise do ciclo de vida de um produto pode oferecer à gestão de resultados e estratégia de planejamento de vendas.

A visão prática obtida por meio da teoria permitiu corroborar a teoria apresentada, pois a empresa analisada, ao realizar sua classificação de clientes, pode obter informações para identificar quais produtos poderão fazer parte do seu mix, qual precificação executar para atender às necessidades de seu público-alvo. Ao considerar que os clientes exigentes anseiam por exclusividade, dessa forma, é importante para a empresa identificar seus produtos para venda e de que forma realizarão sua promoção. Além disso, a análise do ciclo de vida dos produtos, ao ser usado de forma correta, pode fazer com que a empresa possa aproveitar, de maneira mais apropriada, o potencial desses produtos, inclusive no estágio de declínio, em que poucas empresas sabem e conseguem lucrar.

Para um melhor entendimento do assunto, ainda são necessários mais estudos sobre como, por exemplo, uma análise das maneiras como as ferramentas aqui analisadas atuam em outros setores das empresas e também sobre produtos que não permitem um aproveitamento satisfatório após seu declínio no mercado competitivo. Assim, este estudo pretende ser ponto de partida para a elaboração de estudos vindouros.

\section{REFERÊNCIAS}

AREZZO estuda marca 'popular'. Jornal Estadão, São Paulo, 21 set. 2011. Disponível em: <http://economia.estadao.com.br/noticias/geral,arezzo-estuda-marca-popular-imp,775338>. Acesso em: 26/out/2014.

CARAVANTES, Geraldo R.; PANNO, Cláudia C.; KLOECKNER, Mônica C. (2004). Gestão estratégica de resultados: construindo o futuro. Porto Alegre: AGE.

CAVALCANTE, Ângela. Competitividade do setor de moda é debatida no CE. Jornal Diário do Nordeste, Fortaleza, 16 ago. 2013. Disponível em: 
Influência do ciclo de vida do produto em relação à classificação de clientes para planejar estratégias de venda: o caso de um comércio varejista de calçados e acessórios Wellington Pereira Godinho Neto, Rosângela Venâncio Nunes, CharlesWashington Costa de Assis, Rita de Cassia Fonseca, Nayana de Almeida Adriano

<http://diariodonordeste.verdesmares.com.br/cadernos/negocios/competitividade-dosetor-de-moda-e-debatida-no-ce-1.395265>. Acesso em: 27/out/2014.

COBRA, Marcos Henrique Nogueira. (2007). Marketing e moda. São Paulo: Senac.

CORBARI, Ely Célia; MACEDO, Joel de Jesus. (2012). Administração estratégica de custos. Edição digital. Curitiba: lesde. Disponível em: $<$ http://books.google.com.br/books?id=eRQ8z_A3EeYC\&printsec=frontcover\&hl=pt$B R \&$ source $=g b s \_g e \_s u m m a r y \_r \& c a d=0 \# v=0$ epage $\& q f=f a l s e>$.

CRANE, Diana. (2006). A moda e seu papel social. São Paulo: Senac.

GIRÃO, Raimunda Nonata Marques. (2011). A relevância da análise do ciclo de vida do produto para a gestão logística no segmento de moda feminina no Ceará - o caso Colméia Confecções. 30 f. Monografia (Graduação em Administração). Centro Universitário Estácio do Ceará, Fortaleza.

KOTLER, Philip; KELLER, Kevin Lane. (2006). Administração de marketing. São Paulo: Pearson.

LAS CASAS, Alexandre Luzzi. (2004). Marketing de varejo. (3. ed.). São Paulo: Atlas.

LENZI, Fernando César; KIESEL, Márcio Daniel; ZUCCO, Fabrícia Durieux. (2010). Ação empreendedora: como desenvolver e administrar o seu negócio com excelência. São Paulo. Gente.

LORENZO, Francine de. Valor Econômico (SP): Classe $C$ cresce e pressiona preços de serviços. Instituto de Pesquisa Econômica e Aplicada, Brasília, 4 fev. 2013. Disponível em:

$<$ http://www.ipea.gov.br/portal/index.php?option=com_content\&view=article\&id=16847\&l temid=75>. Acesso em: 3/nov/2014.

NASCIMENTO, Juliana Girão do. (2012). Liquidação como estratégia de venda no varejo de moda. 37 f. (Monografia). Graduação tecnológica em Design de Moda. Faculdade Católica do Ceará, Fortaleza.

NOBRE, Rodrigo de Alencar. (2012). Análise da relação entre a obtenção de margem líquida e a geração e distribuição de riqueza aos empregados nas 30 maiores empresas brasileiras em vendas líquidas dos anos de 2009 a 2011. 22 f. (Monografia). Graduação em Ciências Contábeis. Centro Universitário Estácio do Ceará, Fortaleza.

NUNES, Paulo. (2015). Características do tipo de gestão designado por "Gestão por Resultados". Universidade Nova Lisboa. Lisboa-PT. 
Influência do ciclo de vida do produto em relação à classificação de clientes para planejar estratégias de venda: o caso de um comércio varejista de calçados e acessórios Wellington Pereira Godinho Neto, Rosângela Venâncio Nunes, CharlesWashington Costa de Assis, Rita de Cassia Fonseca, Nayana de Almeida Adriano

PINHEIRO, Eduardo Perrone. (2001). Promoção de vendas e merchandising: o esforço integrado no desenvolvimento mercadológico. São Paulo: Ômega.

RIGBY, Darrell K. (2009). Ferramentas de gestão: um guia para executivos. São Paulo. Bain \& Company, Inc.

SCHMID, Erika. (2004). Marketing de varejo de moda: uma ênfase em médias empresas. Rio de Janeiro: Qualitymark.

SERTEK, Paulo; GUINDANI, Roberto Ari; Martins, Tomás Sparano. (2009). Administração e planejamento estratégico. Curitiba: Ibpex.

SILVA, Edna Lúcia da; MENEZES, Estera Muszkat. (2001). Metodologia da pesquisa e elaboração de dissertação. (3. ed.). Florianópolis: Laboratório de Ensino a Distância da UFSC.

SOUZA, Girlene Santos de; SANTOS, Anacleto Ranulfo dos; DIAS, Viviane Borges. (2013). Metodologia da pesquisa científica: a construção do conhecimento e do pensamento científico no processo de aprendizado. Porto Alegre. Animal.

TRIGO, Roberta. (2010). Marketing pessoal e administração de carreira. Bauru. Canal 6.

Data de Submissão: 24/05/2016

Data de Aceite: 24/10/2016 